\title{
PERTUMBUHAN DAN PRODUKSI TANAMAN JAGUNG PROLIFIK PADA BERBAGAI JARAK TANAM DALAM BARIS DENGAN SISTEM TANAM JAJAR LEGOWO
}

\author{
(Growth and Production of Corn Prolified Corn on Various Plants in Row \\ with Legowo Jajar Planting System)
}

\author{
Intan Dwi Lestari ${ }^{1)}$, Abdul Haris ${ }^{2)}$, Sudirman Numba ${ }^{2)}$ \\ ${ }^{1)}$ Magister Agroteknologi Program Pascasarjana UMI \\ ${ }^{2)}$ Fakultas Pertanian Universitas Muslim Indonesia \\ ${ }^{1)}$ Email : Intandwilesta17@gmail.com \\ ${ }^{2)}$ Email : h_abdul_haris@yahoo.com \\ ${ }^{2)}$ Email : numbasudirman@yahoo.co.id
}

\begin{abstract}
This research aimed to determine the effect of spacing on the growth and yield of corn. It was conducted from July to November 2019 at the Experimental Plantation of Cereal Crops Research Institute (BalitSereal), Maros, South Sulawesi. The experimental method used was a randomized block design consisting of 4 treatments: $J 1=(100 \mathrm{~cm} \times 50 \mathrm{~cm}) \times 20 \mathrm{~cm}$, one seed per hole; $J 2=(100 \mathrm{~cm} \times 50 \mathrm{~cm}) \times 30$ $\mathrm{cm}$, alternating between one seed per hole and two seeds per hole; J3= (100 cm $x 50 \mathrm{~cm}) \times 40 \mathrm{~cm}$, two seeds per hole; J4=(100 cm $\times 50 \mathrm{~cm}) \times 15 \mathrm{~cm}$, one seed per hole. The observed variables were planted height, a number of leaves, stem diameter, leaf area index, Anthesis Silking Interval (ASI), length of cob 1 and cob 2, a diameter of cob 1 and cob 2, a weight of shelled seeds/plant, a weight of 100 seeds on cob 1 and cob 2, and production of shelled seeds/hectare. The experimental results showed that plant spacing affected the growth and production of maize. The $J 3$ spacing $(100 \mathrm{~cm} \times 50 \mathrm{~cm}) \times 40 \mathrm{~cm}$ with two seeds per hole significantly affected the leaf area index and gave the highest average stem diameter. The J2 spacing with $(100 \mathrm{~cm} \times 50 \mathrm{~cm}) \times 30 \mathrm{~cm}$ with alternating between one seed per hole, and two seeds per hole produced the highest production in terms of the weight of shelled seeds/plant, weight of 100 seeds and yield of shelled seeds/hectare.
\end{abstract}

Keywords: Corn; spacing; planting system; Jajar Legowo; productivity

\section{PENDAHULUAN}

Tanaman jagung (Zea mays L.) merupakan salah satu dari tiga tanaman sereal utama di dunia yang menempati posisi penting dalam perekonomian maupun ketahanan pangan nasional karena pemanfaatannya yang luas sebagai sumber pangan, pakan ternak dan bahan baku industri. Di Indonesia, jagung merupakan salah satu tanaman penting, ketersediaannya sangat diusahakan oleh berbagai kalangan, mulai dari instansi pemerintah, peneliti dan petani. Kebutuhan jagung nasional hampir 50\% digunakan untuk industri pakan (Sari, 2017). Pada tahun 2020 penggunaan jagung untuk kebutuhan pakan diperkirakan terus meningkat lebih dari $60 \%$ dari total kebutuhan nasional (Badan Litbang Pertanian, 2006). Dalam sistem budidaya jagung, komponen pengaturan jarak tanam diperlukan untuk mendapatkan hasil yang maksimal, tingkat populasi yang optimal dan 
mempermudah dalam perawatan yang telah dirumuskan diatas, maka perlu (Rahmansyah dan Sudiarso, 2018). Salah dilakukan penelitian untuk mengetahui satu teknologi yang dapat dilakukan pengaruh jarak tanam yang tepat agar dalam meningkatkan produktivitas jagung diperoleh pertumbuhan dan hasil tanaman dan menekan biaya produksi adalah jagung yang baik.Penelitian ini bertujuan melalui rekayasa lingkungan tanaman untuk mengetahui pengaruh jarak tanam jagung dengan sistem tanam jajar legowo, terhadap pertumbuhan dan hasil tanaman selain itu menggunakan jarak tanam yang jagung.

tepat, akan meningkatkan produksi jagung Mayadewi (2007). Tanaman jagung yang mempunyai sifat agresivitas dan habitus yang tinggi akan mempunyai daya saing yang kuat. Pengaturan jarak tanam yang baik merupakan salah satu faktor yang dapat dilakukan untuk mengurangi terjadinya kompetisi antara tanaman jagung, baik tanpa mengalami banyak persaingan dalam hal ketersediaan air, unsur-unsur hara dan cahaya matahari secara optimal untuk proses fotosintesis, serta pengisian biji pada tanaman jagung dapat optimal. Berdasarkan permasalahan

\section{BAHAN DAN METODE}

Penelitian dilaksanakan di Kebun Percobaan Balai Penelitian Tanaman Jagung dan Serealia (BalitSereal), Kabupaten Maros, Provinsi Sulawesi Selatan.Penelitian dilaksanakan pada bulan Juli sampai November 2019.

Benih yang digunakan adalah benih jagung hibrida Varietas Nasa-29 (prolifik).

Penelitian ini dilaksanakan dalam bentuk Rancangan Acak Kelompok (RAK) dengan 4 perlakuan yaitu:

$\mathrm{J} 1=(100 \mathrm{~cm} \times 50 \mathrm{~cm}) \times 20 \mathrm{~cm}, 1$ tanaman/lubang.

$\mathrm{J} 2=(100 \mathrm{~cm} \times 50 \mathrm{~cm}) \times 30 \mathrm{~cm}, 1$ tanaman/lubang dan 2 tanaman pada lubang berikutnya.

$\mathrm{J} 3=(100 \mathrm{~cm} \times 50 \mathrm{~cm}) \times 40 \mathrm{~cm}, 2$ tanaman/lubang.

$\mathrm{J} 4=(100 \mathrm{~cm} \times 50 \mathrm{~cm}) \times 15 \mathrm{~cm}, 1$ tanaman/lubang.

Setiap perlakuan diulang tiga kali, pengukuran berbagai peubah yang sehingga terdapat 12 unit diamati.

percobaan.Diambil sampel tetap secara

Pupuk yang digunakan yaitu acak sebanyak 8 tanaman untuk pupuk Urea sebanyak 2 gram/tanaman,

$\mathrm{KCl}$ sebanyak 1,32 gram/tanaman dan 
NPK mutiara (16:16:16) sebanyak 4,56 Peubah yang diamati yaitu Tinggi gram/tanaman. pupuk diberikan secara tanaman $(\mathrm{cm})$, Jumlah daun (helai) dan tugal dengan jarak 7-8 $\mathrm{cm}$ dari jalur Diameter batang $(\mathrm{cm})$, Pengukuran lubang tanam jagung dengan kedalaman dilakukan secara bersamaan pada umur 60 $8-10 \mathrm{~cm}$. HST. Indeks Luas Daun (ILD), diperoleh dengan menggunakan rumus:

$$
\mathrm{ILD}=\frac{\mathrm{LD}}{\text { Luas area }}
$$

Luas daun total diperoleh dengan mengukur panjang dan lebar daun terlebar pada daun ke 8 dari atas pada tanaman jagung dengan menggunakan rumus:

$$
\mathrm{LD}=\mathrm{p} \times 1 \times \mathrm{k}(\text { Pearch dkk. 1975) }
$$

Keterangan: $\mathrm{LD}=$ luas daun total

$\mathrm{p}=$ panjang daun

$1=$ lebar daun terlebar

$\mathrm{k}=$ konstanta $(9,39)$

Anthesis Silking Interval (ASI), Produksi pipilan/hektar (ton/ha) Panjang tongkol $(\mathrm{cm})$, Diameter tongkol Diperoleh dengan mengkonversi berat biji (cm), Bobot biji pipilan/tanaman (gram), pipilan/tongkol.

Bobot 100 biji (gram).

$$
\text { Ton/ha }=\frac{10.000}{\begin{array}{c}
\text { Luas plot } \\
\text { (panen) }
\end{array}} \mathrm{X} \text { berat biji pipilan/tongkol }
$$

\section{HASIL DAN PEMBAHASAN}

\section{Tinggi Tanaman}

Berdasarkan hasil sidik ragam bahwa perlakuan jarak tanam tidakberpengaruh nyata terhadap tinggi tanaman jagung.

Gambar 1 menunjukkan bahwa tinggi tanaman yang cenderung lebih tinggi diperoleh pada jarak tanam $\mathrm{J} 2=$ $(100 \mathrm{~cm} \times 50 \mathrm{~cm}) \times 30 \mathrm{~cm}$ yaitu 223,20 $\mathrm{cm}$, sedangkan yang terendah adalah jarak tanam $\mathrm{J} 4=(100 \mathrm{~cm} \times 50 \mathrm{~cm}) \times 15 \mathrm{~cm}$, yaitu $208,95 \mathrm{~cm}$.

Pada penelitian ini mampu memberikan pertumbuhan yang baik, tetapi hasilnya tidak berbeda nyata.Pertumbuhan tinggi tanaman yang baik dapat mempengaruhi intensitas cahaya matahari yang diterima oleh tanaman jagung. Semakin mudah tanaman mendapatkan akses cahaya matahari, maka akan semakin berpengaruh terhadap banyaknya energi 
yang digunakan dalam proses fotosintesis. mempengaruhi pertumbuhan dan Selain itu, penyerapan unsur hara yang perkembangan tanaman jagung. cukup dan tidak berlebihan akan

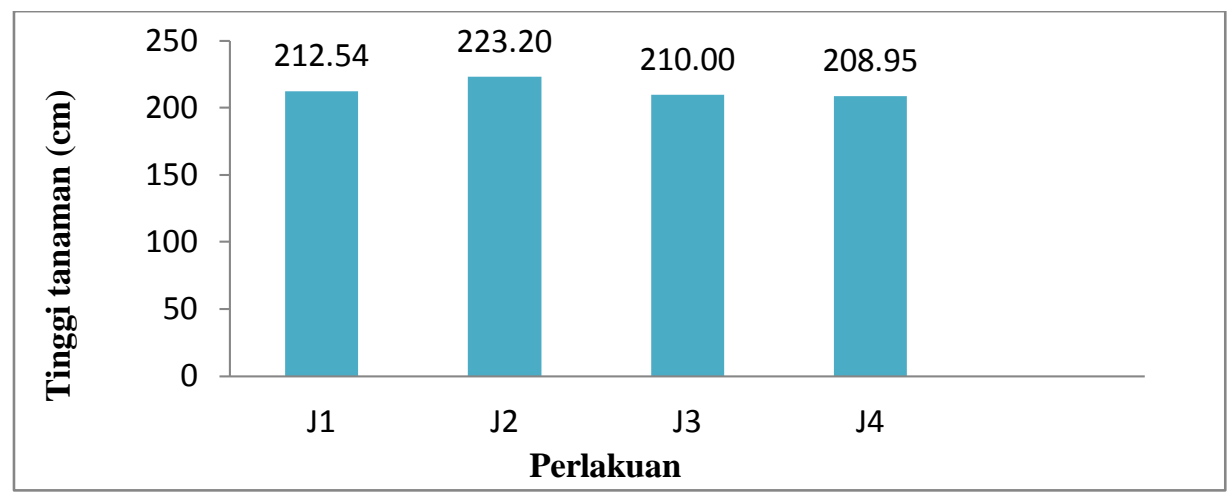

Gambar 1 : Rata-rata tinggi tanaman $(\mathrm{cm})$ terhadap berbagai jarak tanam

Jumlah Daun

Berdasarkan hasil sidik ragam

bahwa perlakuan jarak tanam tidak berpengaruh nyata terhadap jumlah daun tanaman jagung.

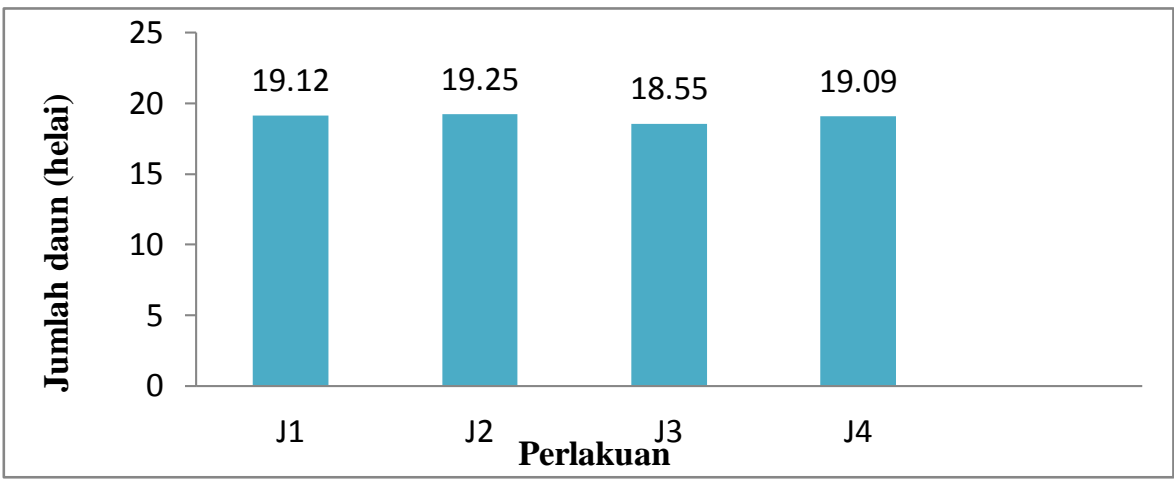

Gambar 2 : Rata-rata jumlah daun (helai) terhadap berbagai jarak tanam

Gambar 2 menunjukkan bahwa tanam $\mathrm{J} 3=(100 \mathrm{~cm} \times 50 \mathrm{~cm}) \times 40 \mathrm{~cm}$, jumlah daun yang cenderung lebih tinggi yaitu 18,55 helai.

diperoleh pada jarak tanam $\mathrm{J} 2=(100 \mathrm{~cm} \mathrm{x}$ Kerapatan tanaman akan $50 \mathrm{~cm})$ x $30 \mathrm{~cm}$ yaitu 19,25 helai, mempengaruhi penampilan dan produksi sedangkan yang terendah adalah jarak jagung terutama karena koefisien penggunaan cahaya yang maksimum di 
awal pertumbuhan, hal ini disebabkan Diameter Batang

pertumbuhan yang konsisten dari jumlah

daun tanaman jagung setiap bukunya,

sehingga tidak di temukannya pengaruh

nyata pada pengamatan.

Berdasarkan hasil sidik ragam

bahwa perlakuan jarak tanam tidak berpengaruh nyata terhadap diameter batang tanaman jagung.

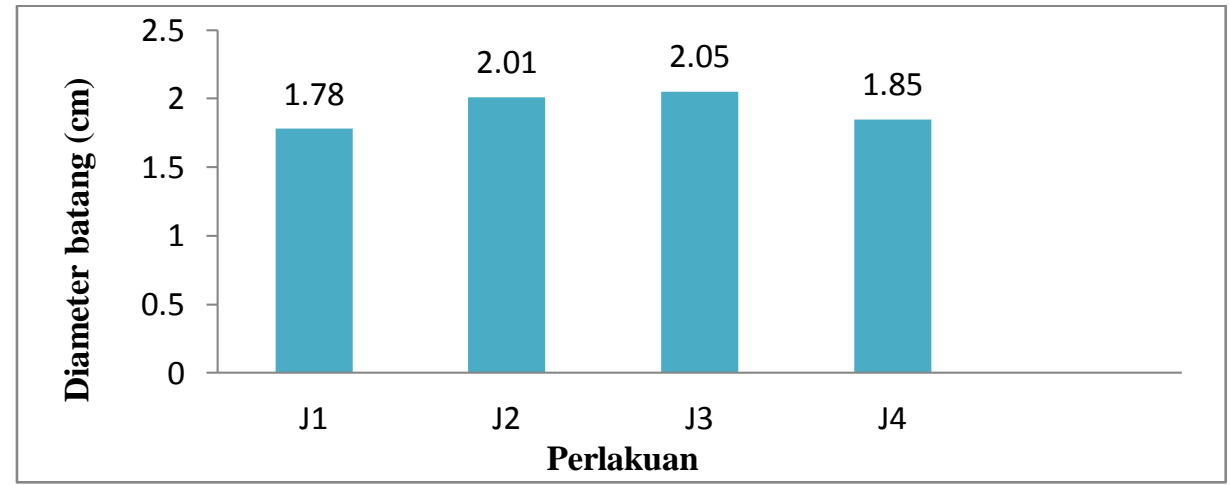

Gambar 3 : Rata-rata diameter batang $(\mathrm{cm})$ terhadap berbagai jarak tanam

Gambar 3 menunjukkan bahwa diameter batang yang cenderung lebih tinggi diperoleh pada jarak tanam J3= $(100 \mathrm{~cm} \times 50 \mathrm{~cm}) \times 40 \mathrm{~cm}$ yaitu $2,05 \mathrm{~cm}$, sedangkan yang terendah adalah jarak tanam $\mathrm{J} 1=(100 \mathrm{~cm} \times 50 \mathrm{~cm}) \times 20 \mathrm{~cm}$, yaitu $1,78 \mathrm{~cm}$.

Diameter batang tanaman jagung tidak terlalu besar karena tanaman ini merupakan tanaman monokotil.Pada batang monokotil, epidermis terdiri dari satu lapis sel, batas antara korteks dan stele umumnya tidak jelas.Pada stele monokotil terdapat ikatan pembuluh yang menyebar dan bertipe kolateral tertutup yang artinya di antara xilem dan floem tidak ditemukan kambium. Tidak adanya kambium pada monokotil menyebabkan batang monokotil tidak dapat tumbuh membesar, dengan perkataan lain tidak terjadi pertumbuhan menebal sekunder (Silaban, 2013).

\section{Indeks Luas Daun (ILD)}

Berdasarkan hasil sidik ragam bahwa perlakuan jarak tanam sangat berpengaruh nyata terhadap Indeks Luas Daun (ILD) tanaman jagung. 
Tabel 1. Rata-rata Indeks Luas Daun (ILD) pada berbagai jarak tanam pada tanaman jagung

\begin{tabular}{lcc}
\hline \hline Jarak tanam Legowo 2:1 & Indeks Luas Daun & NP BNT $_{0,05}$ \\
\hline \hline$(\mathrm{J} 1)(100 \mathrm{~cm} \times 50 \mathrm{~cm}) \times 20 \mathrm{~cm}$ & $7,03^{\mathrm{b}}$ & \\
$(\mathrm{J} 2)(100 \mathrm{~cm} \times 50 \mathrm{~cm}) \times 30 \mathrm{~cm}$ & $5,76^{\mathrm{a}} 0,85$ \\
$(\mathrm{~J} 3)(100 \mathrm{~cm} \times 50 \mathrm{~cm}) \times 40 \mathrm{~cm}$ & $9,24^{\mathrm{c}}$ & \\
$(\mathrm{J} 4)(100 \mathrm{~cm} \times 50 \mathrm{~cm}) \times 15 \mathrm{~cm}$ & $6,47^{\mathrm{ab}}$ & \\
\hline Ke
\end{tabular}

$\overline{\text { Keterangan : Angka yang diikuti oleh huruf yang sama tidak berbeda nyata berdasarkan uji Beda Nyata }}$ Terkecil $\left(\mathrm{BNT}_{0,05}\right)$

Tabel 1 menunjukkan bahwa rata- jagung dipengaruhi sinar matahari rata indek luas daun (ILD), tertinggi langsung, dengan demikian hasil yang adalah jarak tanam $\mathrm{J} 3=(100 \mathrm{~cm} \times 50 \mathrm{~cm})$ diperoleh akan maksimal (Yudiwanti, x $40 \mathrm{~cm}$ yaitu 9,24 m, sedangkan yang 2010).

terendah jarak tanam $\mathrm{J} 2=(100 \mathrm{~cm} \times 50$ Anthesis Silking Interval (ASI) $\mathrm{cm})$ x $30 \mathrm{~cm}$ yaitu $5,76 \mathrm{~m}$. Hal tersebut

Berdasarkan hasil sidik ragam disebabkan jarak antara tanaman sesuai bahwa perlakuan jarak tanam tidak kebutuhan pertanaman dalam berpengaruh nyata terhadap Anthesis pertumbuhannya. Luas daun tanaman Silking Interval (ASI) tanaman jagung.

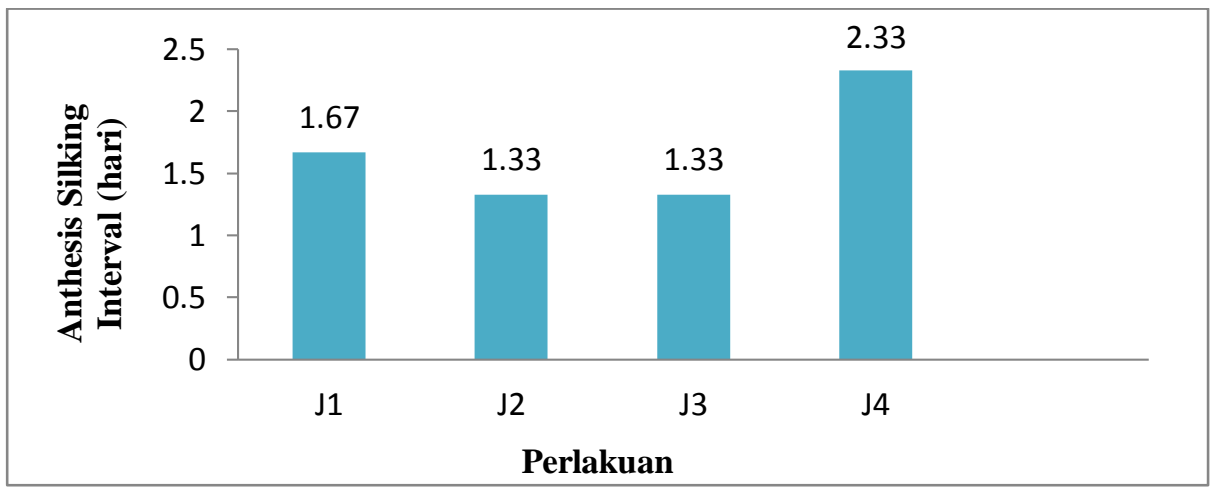

Gambar 4 : Rata-rata Anthesis Silking Interval (hari) terhadap berbagai jarak tanam

Gambar 4 menunjukkan bahwa $\mathrm{cm}$ yaitu 2,33 hari sedangkan yang Anthesis Silking Interval (ASI) yang terendah adalah jarak tanam $J 1=(100 \mathrm{~cm}$ cenderung lebih tinggi diperoleh pada x $50 \mathrm{~cm}) \times 20 \mathrm{~cm}$ dan $(100 \mathrm{~cm}$ x $50 \mathrm{~cm}) \times$ jarak tanam $\mathbf{J} 4=(100 \mathrm{~cm} \times 50 \mathrm{~cm}) \times 1530 \mathrm{~cm}$, yaitu 1,33 hari. 


\section{Panjang Tongkol}

Berdasarkan hasil sidik ragam bahwa perlakuan jarak tanam tidak berpengaruh nyata terhadap panjang

tongkol tanaman jagung.

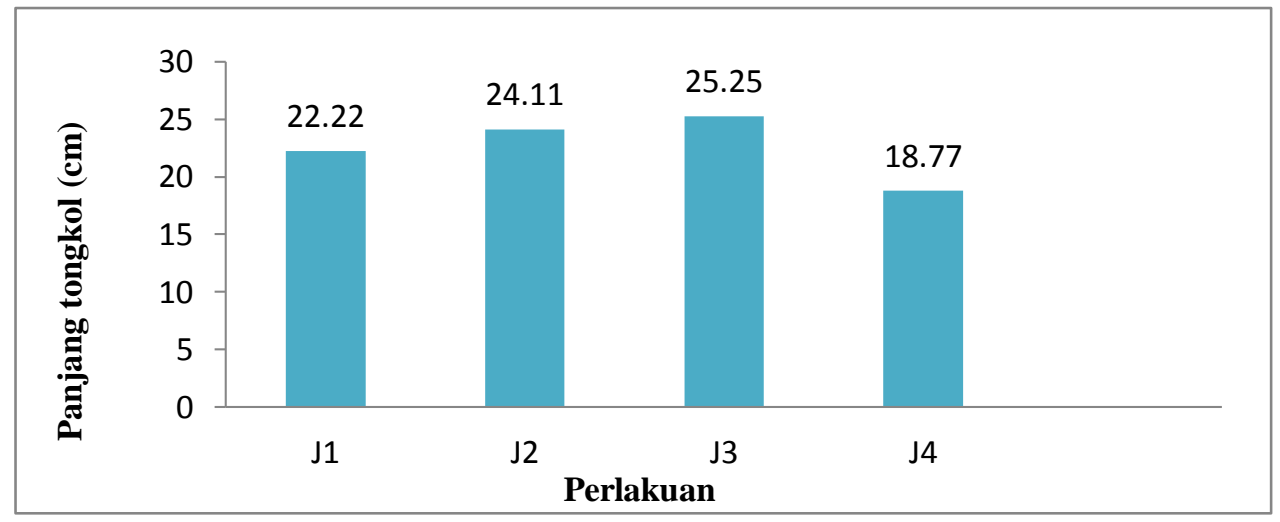

Gambar 5 : Rata-rata panjang tongkol $(\mathrm{cm})$ terhadap berbagai jarak tanam

Gambar 5 menunjukkan bahwa hasil tanaman jagung. Hal ini di kuatkan panjang tongkol yang cenderung lebih oleh Haruna, dkk (2018) bahwa Varietas tinggi diperoleh pada jarak tanam J3= Nasa 29 merupakan varietas jagung yang $(100 \mathrm{~cm} \times 50 \mathrm{~cm}) \times 40 \mathrm{~cm}$ yaitu $25,25 \mathrm{~cm}$, memiliki panjang tongkol terpanjang sedangkan yang terendah adalah jarak dibandingkan varietas Bima URI 29 dan tanam $\mathrm{J} 4=(100 \mathrm{~cm} \times 50 \mathrm{~cm}) \times 15 \mathrm{~cm}, \quad$ Bisi 2.

yaitu $18,77 \mathrm{~cm}$.

Hal tersebut disebabkan jarak antara tanaman sesuai

kebutuhan pertanaman.Selain pengaruh jarak tanam yang sesuai dengan pertumbuhan tanaman jagung, varietas juga mempengaruhi pada

\section{Diameter Tongkol}

Berdasarkan hasil sidik ragam bahwa perlakuan jarak tanam tidak berpengaruh nyata terhadap diameter tongkol tanaman jagung. 


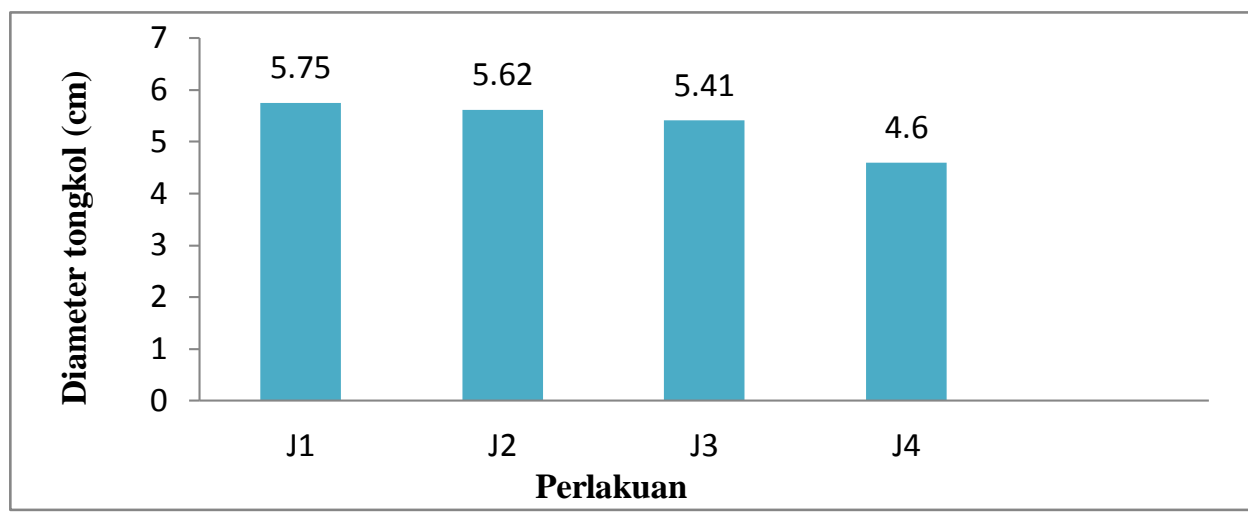

Gambar 6 : Rata-rata diameter tongkol $(\mathrm{cm})$ terhadap berbagai jarak tanam

Gambar 6 menunjukkan bahwa diameter tongkol yang cenderung lebih tinggi diperoleh pada jarak tanam $\mathrm{J} 1=$ bahwa perlakuan jarak tanam tidak $(100 \mathrm{~cm} \times 50 \mathrm{~cm}) \times 20 \mathrm{~cm}$ yaitu $5,75 \mathrm{~cm}$, berpengaruh nyata terhadap bobot biji sedangkan yang terendah adalah jarak pipilan/tanaman jagung. tanam $\mathrm{J} 4=(100 \mathrm{~cm} \times 50 \mathrm{~cm}) \times 15 \mathrm{~cm}$, yaitu $4,60 \mathrm{~cm}$.

\section{Bobot Biji Pipilan/tanaman}

Berdasarkan hasil sidikragam ji 
nyata terhadap Bobot 100 Biji tanaman jagung.

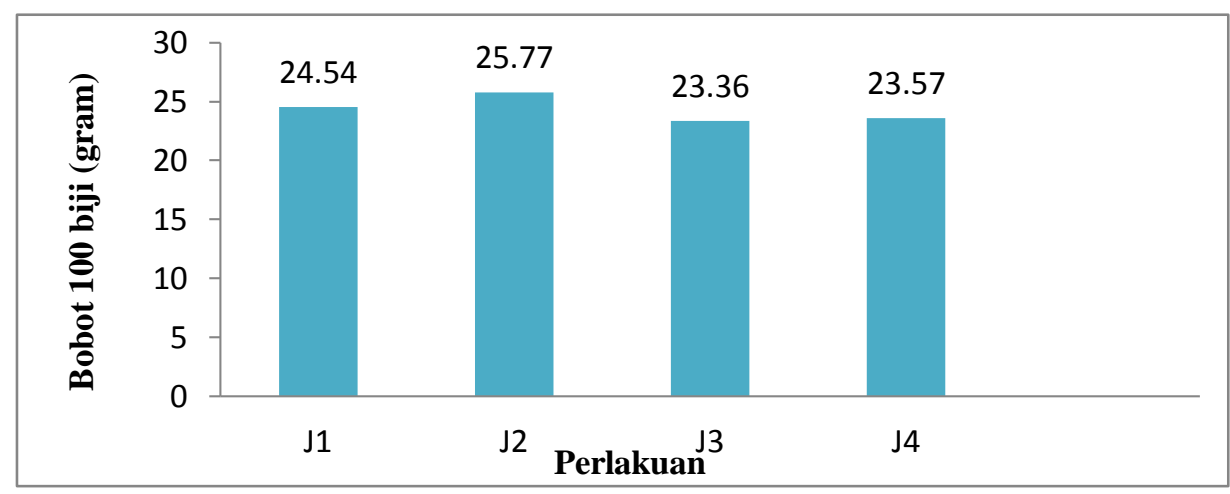

Gambar 8 : Rata-rata bobot 100 biji (gram) terhadap berbagai jarak tanam

Gambar 8 menunjukkan bahwa menyatakan bahwa jika suatu tanaman bobot 100 biji yang cenderung lebih tinggi dapat berkembang optimal pada fase diperoleh pada jarak tanam $\mathrm{J} 2=(100 \mathrm{~cm} \times$ vegetatif, cadangan hara yang tersimpan $50 \mathrm{~cm})$ x $30 \mathrm{~cm}$ yaitu 25,77 gram, pada biji cenderung lebih sedikit karena sedangkan yang terendah adalah jarak hara tersedia telah dipakai secara optimal tanam $\mathrm{J} 3=(100 \mathrm{~cm} \times 50 \mathrm{~cm}) \times 40 \mathrm{~cm}$, untuk pertumbuhan tanaman. yaitu 23,36 gram.

Hal ini dapat terjadi karena hara tersedia tidak diserap secara optimal, sehingga hara tersedia sedikit saat memasuki fase produksi.Hidayati dan Fathur (2009) pipilan/hektar tanaman jagung.

\section{Produksi Pipilan/Hektar}

Berdasarkan hasil sidikragam bahwa perlakuan jarak tanam tidak berpengaruh nyata terhadap produksi

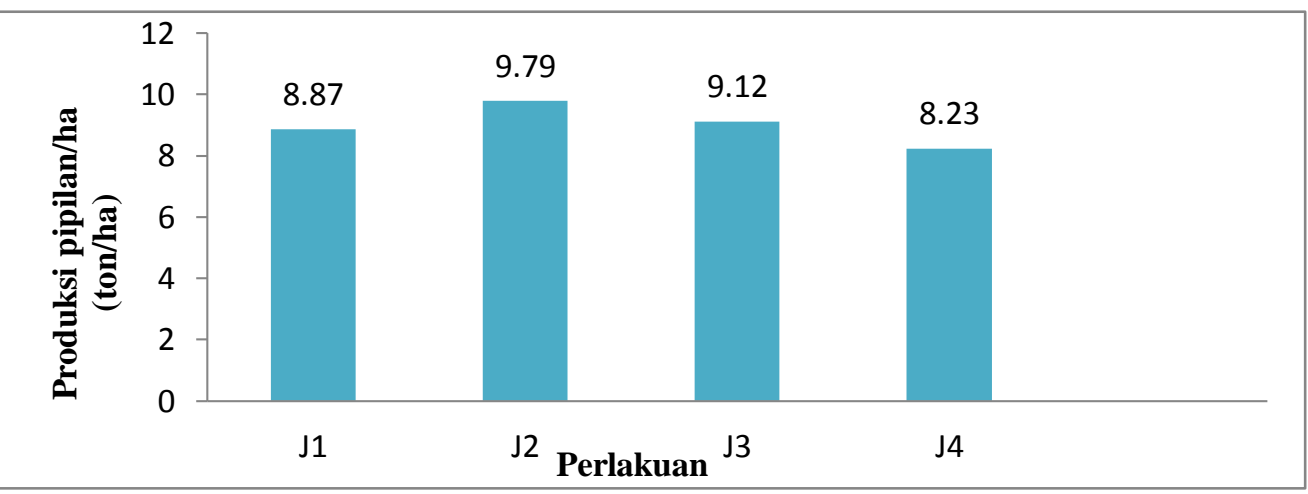

Gambar 9 : Rata-rata produksi pipilan/hektar (ton/ha) terhadap berbagai jarak tanam 
Gambar 9 menunjukkan bahwa produksi pipilan/hektaryang cenderung lebih tinggi diperoleh pada jarak tanam $\mathrm{J} 2=(100 \mathrm{~cm} \times 50 \mathrm{~cm}) \times 30 \mathrm{~cm}$, yaitu 9,79 ton/ha dan yang terendah adalah jarak tanam $\mathrm{J} 4=(100 \mathrm{~cm} \times 50 \mathrm{~cm}) \times 15 \mathrm{~cm}$, yaitu 8,23 ton/ha.

Pada keadaaan yang menguntungkan, fotosintat yang dihasilkan dapat dimanfaatkan untuk pertumbuhan dan perkembangan tanaman, setelah tanaman jagung memasuki fase generatif fotosintat yang dihasilkan akan lebih banyak dikirim ke biji, maka biji akan menjadi lebih berat. Hal tersebut berarti bahwa populasi yang sama tetapi penataan jarak tanam yang berbeda akan memberikan hasil biji kering yang berbeda pula. Hal ini banyak dipengaruhi oleh tingkat penyerapan sinar matahari oleh daun, yang akan digunakan untuk proses fotosintesis. Areal yang longgar akan lebih mempermudah tanaman dalam menyerap sinar matahari, unsur hara dan air yang dibutuhkan tanaman untuk fotosintesis dan menghasilkan asimilat untuk memproduksi biji.

\section{KESIMPULAN}

1. Jarak tanam $(100 \mathrm{~cm} \times 50 \mathrm{~cm}) \times 40$ $\mathrm{cm}$, dua biji per lubang, berpengaruh sangat nyata terhadap indeks luas daun tanaman jagung dan menunjukkan rata-rata tertinggi pada diameter batang.

2. Jarak tanam $(100 \mathrm{~cm} \times 50 \mathrm{~cm}) \times 30$ $\mathrm{cm}$, satu biji per lubang dan dua biji pada lubang berikutnya, memberikan hasil terbaik yang diperlihatkan oleh bobot biji pipilan/tanaman, bobot 100 biji dan produksi pipilan/ha tertinggi.

\section{DAFTAR PUSTAKA}

Haruna, A. H., St. Subaedah dan St. Sabahannur. 2018. Respon Beberapa Varietas Tanaman Jagung (Zea Mays L) Pada Berbagai Sistem Tanam.Jurnal Agrotek Vol. 2 No. 2. Balai Penelitian Tanaman Serealia, Maros: Fakultas Pertanian, Universitas Muslim Indonesia Makassar.

Hidayat, A. N. 2017. Pengaruh Sistem Tanam Jajar Legowo Dan Waktu Penyiangan Terhadap Pertumbuhan Dan Hasil Tanaman Jagung Manis (Zea mays L. var. saccharata Sturt). SKRIPSI: Fakultas Pertanian, Universitas Muria Kudus.

Rahmansyah, B. dan Sudiarso. 2018. Pengaruh Teknik Jajar Legowo Dan Berbagai Jarak Tanam Pada Pertumbuhan Dan Hasil Tanaman Jagung Bisi-6 (Zea Mays Identata). Departement of Agronomy.Faculty of Agriculture.Brawijaya University. Malang.

Sari, P. M. 2017. Peningkatan Produksi Dan Mutu Benih Jagung Hibrida Melalui Aplikasi Pupuk N, P, K Dan 

dalam Baris dengan Sistem Jajar Legowo

Bakteri Probiotik. Institut Pertanian Bogor. Bogor: Departemen Agronomi Dan Hortikultura.

Wahyudin, A, Y. Yuwariah, F.Y. Wicaksono dan R.A.G. Bajri. 2017. Respon jagung (Zea mays L.) akibat jarak tanam pada sistem tanam legowo (2:1) dan berbagai dosis pupuk nitrogen pada tanah inceptisol Jatinango. Department of Crop Science, Padjadjaran University. Bandung. 